\title{
NEURAL NETWORK PREDICTIVE CONTROL BASED POWER SYSTEM STABILIZER
}

\author{
Ali Mohamed Yousef Ali \\ Electrical Engineering Dept., Faculty of Engineering, Assiut University, \\ Egypt,Drali_yousef@yahoo.com
}

(Received July 26, 2011 Accepted August 18, 2011)

The present paper investigates the power system stabilizer based on neural predictive control for improving power system dynamic performance over a wide range of operating conditions. In this study a design and application of the neural network model predictive controller (NN-MPC) on a simple power system composed of a synchronous generator connected to an infinite bus through a transmission line is proposed. The synchronous machine is represented in detail, taking into account the effect of the machine saliency and the damper winding. Neural network model predictive control combines reliable prediction of neural network model with excellent performance of model predictive control using nonlinear Levenberg-Marquardt optimization. This control system is used the rotor speed deviation as a feedback signal. Furthermore, the used performance system of the proposed controller is compared with the system performance using conventional one (PID controller) through simulation studies. Digital simulation has been carried out in order to validate the effectiveness proposed NN-MPC power system stabilizer for achieving excellent performance. The results demonstrate that the effectiveness and superiority of the proposed controller in terms of fast response and small settling time.

KEYWORDS: Power system stabilizer, NN_MPC control and single synchronous machine infinite bus systems

\section{LIST OF SYMBOLS}

$H$ Inertia constant of the machine, in second

$i_{d} \quad \mathrm{~d}$-axis armature current, in p.u.

$i_{f} \quad$ Field winding current, in p.u.

$i_{k d}, \quad \mathrm{~d}$ - and q-axis damper winding

$i_{k q} \quad$ currents, in p.u.

$i_{q} \quad$ q-axis armature current, in p.u.

$r_{e} \quad$ Series resistance of transmission system, in p.u.

$r_{f}, r_{m} \quad$ Field and armature resistance, in p.u.

$T_{e} \quad$ Machine electromagnetic torque, in p.u.
$X_{k d} \quad$ The d-axis damper winding self reactance, in p.u.

$X_{k q} \quad$ The q-axis damper winding self reactance, in p.u.

$X_{q} \quad$ q-axis synchronous reactance, in p.u.

$X_{d}^{\prime} \quad \mathrm{d}$-axis transient reactance, in p.u.

$X_{d}^{\prime \prime} \quad$ d-axis subtransient reactance, in p.u.

$\delta$ Rotor displacement angle, in radian

$\omega \quad$ Rotor instantaneous angular velocity, in rad./sec

$\omega_{o}$ Rotor synchronous speed, in $\mathrm{rad} / \mathrm{sec}$ 


\begin{tabular}{|clcl|}
\hline$T_{m}$ & Shaft torque, in p.u. & $\Psi_{d}$ & $\begin{array}{l}\text { The d-axis armature flux linkage in } \\
\text { p.u. }\end{array}$ \\
$V_{f}$ & Field voltage, in p.u. & $\Psi_{f}$ & The field winding flux linkage in p.u. \\
$V_{t}$ & Machine terminal voltage, in p.u. & $\Psi_{k d}$ & $\begin{array}{l}\text { The d-axis damper winding flux } \\
\text { linkage in p.u. }\end{array}$ \\
$X_{d}$ & $\begin{array}{l}\text { d-axis synchronous reactance, in } \\
\text { p.u. }\end{array}$ & $\Psi_{k q}$ & $\begin{array}{l}\text { The q-axis damper winding flux } \\
\text { linkage in p.u. }\end{array}$ \\
$X_{e}$ & $\begin{array}{l}\text { Series reactance of transmission } \\
\text { system, in p.u. }\end{array}$ & $\Psi_{q}$ & $\begin{array}{l}\text { The q-axis armature flux linkage in } \\
\text { p.u. }\end{array}$ \\
\end{tabular}

\section{INTRODCTION}

Power system stabilizers (PSSs) have been widely used as supplementary controllers to provide extra damping for synchronous generators in electrical power system. Conventional power system stabilizer (CPSSs) are used to damp out small signal oscillations and they are designed based on a model which is linearized around a particular operating point. Conventional design tunes the gain and time constants of the PSS, which are mostly lead-lag compensator, using modal frequency techniques [1-3]. The feedback signal is subtracted from the reference to determine the error signal. Due to the complexity of the mathematics, the conventional control methods were used mostly for single-input-single-output system. Modern control methods were extremely successful because they could be efficiently implemented on computers, they could handle multi-input-multi-output system, and they could be optimized [4-7]. With the development of numerical algorithms for solving linear matrix inequality (LMI) problem in the last few years, the LMI approach has emerged as a useful tool for solving a wide range variety of control problems.

Predictive control is now widely used in industry and a large number of implementation algorithms. Most of the control algorithms use an explicit process model to predict the future behavior of a plant and because of this, the term model predictive control (MPC) is often utilized [8-10]. The most important advantage of the MPC technology comes from the process model itself, which allows the controller to deal with an exact replica of the real process dynamics, implying a much better control quality. The inclusion of the constraints is the feature that most clearly distinguishes MPC from other process control techniques, leading to a tighter control and a more reliable controller. Another important characteristic, which contributes to the success of the MPC technology, is that the MPC algorithms consider plant behavior over a future horizon in time. Thus, the effects of both feed forward and feedback disturbances can be anticipated and eliminated, fact, which permits the controller to drive the process output more closely to the reference trajectory.

Several versions of MPC techniques are model algorithmic control (MAC) [11], dynamic matrix control (DMC) [12], and internal model control (IMC) [13]. Although the above techniques differ from each other in some details, they are fundamentally the same, because all of them are based on linear process modeling.

The Neural Network Model Predictive Control (NN-MPC) is another typical and straightforward application of neural networks to nonlinear control. When a neural network is combined with MPC approach, it is used as a forward process model for the 
prediction of process output $[14,15]$. Neural network model predictive control has been applied on the process control as chemical, industry applications. But, applying MPC on power system stability and control is still very slightly used [16-19].

The main objective of this study is to investigate the application of neural network model predictive controller on the single synchronous machine connected to an infinite bus power system. The system is modeled and the NN-MPC is designed and applied on the system. A comparison between the system performance obtained when using the proposed NN-MPC controller and the performance obtain using PID controller at different operating conditions is presented and evaluated for power system. The feasibility and effectiveness of the proposed controller have been demonstrated through computer simulations. Simulation results have NN-MPC proved that the proposed controller can give better overall performance. Simulation results show also that the NN-MPC gives promising results.

\section{POWER SYSTEM MODEL}

Figure 1 shows a synchronous machine with salient poles and damper windings represented in rotating $\mathrm{d}-\mathrm{q}$ axis coordinates. The coordinates are fixed on the rotor and rotate with it. The non-linear differential equations of unsaturated salient pole synchronous machine can be expressed as [1]

$$
\begin{aligned}
& \frac{1}{\omega_{o}} \dot{\Psi}_{f}=V_{f}-r_{f} . i_{f} \\
& \frac{1}{\omega_{o}} \dot{\Psi}_{d}=V_{t d}+r_{m} . i_{d}+\frac{\omega}{\omega_{o}} \Psi_{q} \\
& \frac{1}{\omega_{o}} \dot{\Psi}_{k d}=-r_{k d} \cdot i_{k d} \\
& \frac{1}{\omega_{o}} \dot{\Psi}_{q}=V_{t q}+r_{m} \cdot i_{q}-\frac{\omega}{\omega_{o}} \Psi_{d} \\
& \frac{1}{\omega_{o}} \dot{\Psi}_{k q}=-r_{k q} . i_{k q} \\
& \dot{\delta}=\omega_{o}-\omega_{o} \\
& \dot{\omega}=\frac{\omega_{o}}{2 H}\left(T_{m}-T_{e}\right)
\end{aligned}
$$

The non-linear differential equations described above from Eqns. (1-7) can be linearized around an operating point become linearized algebraic equations as follows:

$$
\begin{aligned}
& \Delta T_{e}=\Psi_{d o} \Delta i_{q}+I_{q o} \Delta \Psi_{d}-\Psi_{q o} \Delta i_{d}-I_{d o} \Delta \Psi_{q} \\
& \Delta v_{t d}=V_{b} \cos \delta_{o} \Delta \delta+r_{e} \Delta i_{d}-x_{e} \Delta i_{q} \\
& \Delta v_{t q}=-V_{b} \sin \delta_{o} \Delta \delta+r_{e} \Delta i_{q}+x_{e} \Delta i_{d}
\end{aligned}
$$




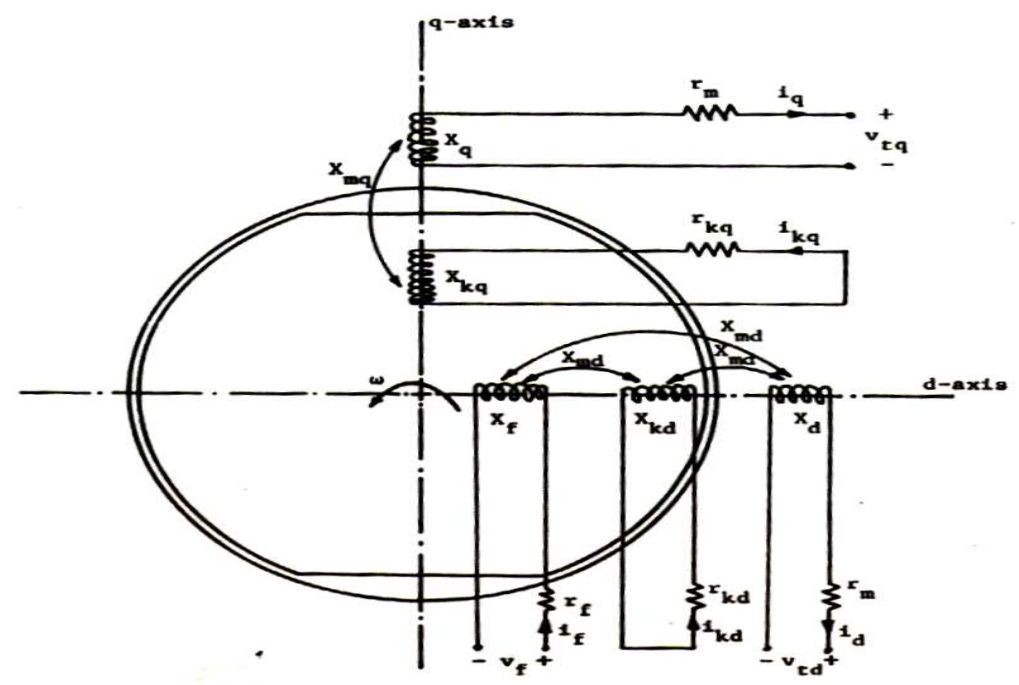

Fig. 1: Representation of synchronous machine in d-q axis coordinate

The relation between fluxes and currents can be derived from the following matrix [1],

$$
\left[\begin{array}{c}
\Delta \Psi_{\mathrm{f}} \\
\Delta \Psi_{\mathrm{d}} \\
\Delta \Psi_{\mathrm{kd}} \\
\Delta \Psi_{\mathrm{q}} \\
\Delta \Psi_{\mathrm{kq}}
\end{array}\right]=\left[\begin{array}{ccccc}
x_{f} & -x_{m d} & x_{m d} & 0 & 0 \\
x_{m d} & -x_{d} & x_{m d} & 0 & 0 \\
x_{m d} & -x_{m d} & x_{k d} & 0 & 0 \\
0 & 0 & 0 & -x_{q} & x_{m q} \\
0 & 0 & 0 & -x_{m q} & x_{k q}
\end{array}\right]\left[\begin{array}{c}
\Delta i_{f} \\
\Delta i_{d} \\
\Delta i_{k d} \\
\Delta i_{q} \\
\Delta i_{k q}
\end{array}\right]
$$

From Eqn. (11), the currents can be derived as a function of fluxes. These yields

$$
\begin{aligned}
& \Delta i_{f}=a_{6} \Delta \Psi_{f}+a_{7} \Delta \Psi_{k d}+a_{8} \Delta \Psi_{d} \\
& \Delta i_{d}=a_{3} \Delta \Psi_{f}+a_{4} \Delta \Psi_{k d}+a_{5} \Delta \Psi_{d} \\
& \Delta i_{k d}=c_{1} \Delta \Psi_{f}+c_{2} \Delta \Psi_{k d}+c_{3} \Delta \Psi_{d} \\
& \Delta i_{q}=b_{1} \Delta \Psi_{q}+b_{2} \Delta \Psi_{k q} \\
& \Delta i_{k q}=b_{3} \Delta \Psi_{q}+b_{4} \Delta \Psi_{k q}
\end{aligned}
$$

The linearized model for this system can be written in the state space form as::

$$
\begin{aligned}
x & =A x+B_{11} u+B_{22} \Delta T_{m} \\
y & =C x+D u+\theta
\end{aligned}
$$

Where; 


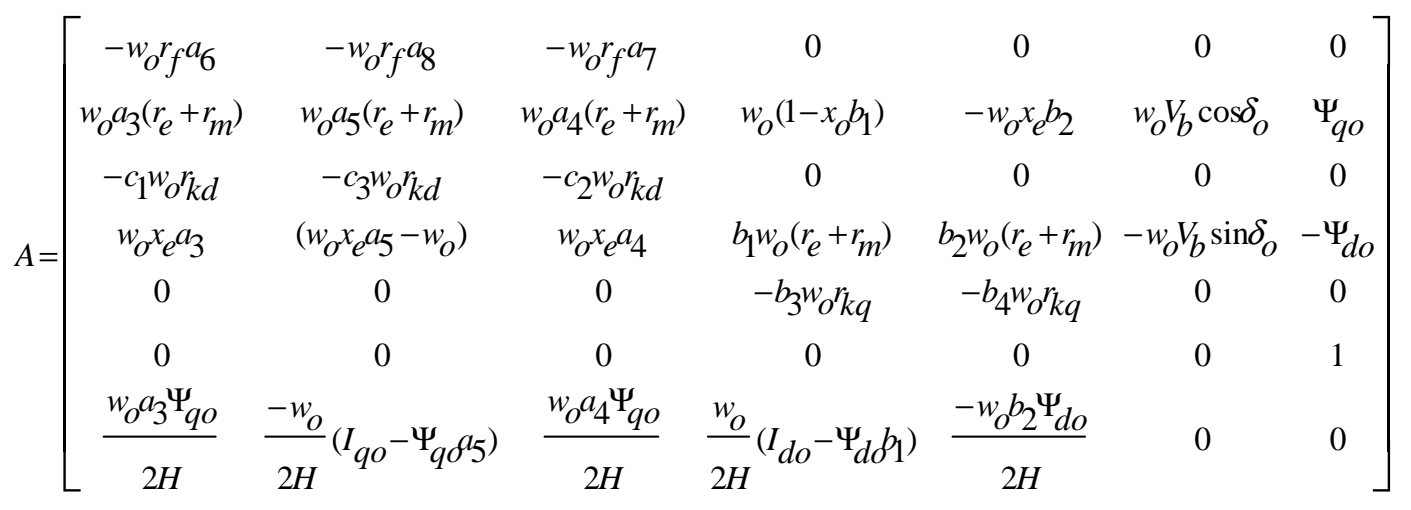

$x=\left[\begin{array}{lllllll}\Delta \Psi_{f} & \Delta \Psi_{d} & \Delta \Psi_{k d} & \Delta \Psi_{q} & \Delta \Psi_{k q} & \Delta \delta & \Delta \omega\end{array}\right]^{T}$, are the system states

$\mathrm{u}$ is the control signal

$\theta=$ is the sensor noise

$B_{11}=\left[\begin{array}{lllllll}w_{o} & 0 & 0 & 0 & 0 & 0 & 0\end{array}\right]^{T}$, is the input vector

$B_{22}=\left[\begin{array}{llllllll}0 & 0 & 0 & 0 & 0 & 0 & w_{o} / 2 H\end{array}\right]^{T}$, is the disturbance vector

The mathematical coefficients $\mathrm{a}_{1}, \mathrm{a}_{2}, \ldots .$, and $\mathrm{c}_{3}$ can be summarized as follows [2]:

$$
\begin{aligned}
& a_{1}=x_{f} x_{d} x_{k d} / x_{m d}-x_{m d} x_{f}-x_{k d} x_{m d}+2 x_{m d}^{2}-x_{m d} x_{d} \\
& a_{2}=\left(x_{f} x_{m d}-x_{m d}^{2}-x_{f} x_{d}+x_{d} x_{m d}\right) \\
& a_{3}=\left(\left(x_{m d}-x_{d}\right) / a_{2}\right)\left(1-\left(\left(x_{f} x_{d} x_{k d} / x_{m d}-x_{k d} x_{f}+x_{m d}^{2}-x_{m d} x_{d}\right) / a_{1}\right)\right. \\
& a_{4}=\frac{-1}{a_{2}}\left\{x_{f} / x_{m d}\left(x_{m d}-x_{d}\right)+\left(x_{d} x_{f} / x_{m d}-x_{m d}\right)\left(\left[x_{f} x_{d} x_{k d} / x_{m d}-x_{k d} x_{f}+x_{m d}^{2}-x_{m d} x_{d}\right] / a_{1}\right)\right\} \\
& a_{5}=\frac{-1}{a_{2}}\left\{\left(x_{m d}-x_{f}\right)\left(\left(x_{f} x_{d} x_{k d} / x_{m d}-x_{k d} x_{f}+x_{m d}^{2}-x_{m d} x_{d}\right) / a_{1}\right)\right\} \\
& a_{6}=1 / x_{f}+a_{3} x_{m d} / x_{f}-x_{m d} / x_{f}\left(x_{m d}-x_{d}\right) / a_{1} \\
& a_{7}=a_{4} x_{m d} / x_{f}-x_{m d} / x_{f}\left\{\left(x_{d} x_{f} / x_{m d}-x_{m d}\right) / a_{1}\right\} \\
& a_{8}=a_{5} x_{m d} / x_{f}-x_{m d} / x_{f}\left\{\left(x_{m d}-x_{f}\right) / a_{1}\right\} \\
& b_{1}=x_{m q}^{2} /\left(x_{q}\left(x_{m q}^{2}-x_{k q} x_{q}\right)\right)-1 / x_{q} \\
& b_{2}=-x_{m q} /\left(x_{m q}^{2}-x_{k q} x_{q}\right) \\
& b_{3}=-b_{2} \\
& b_{4}=-x_{q} /\left(x_{m q}^{2}-x_{k q} x_{q}\right) \\
& c_{1}=\left(x_{m d}-x_{d}\right) / a_{1} \\
& c_{2}=\left(x_{d} x_{f} / x_{m d}-x_{m d}\right) / a_{1}
\end{aligned}
$$


$c_{3}=\left(x_{m d}-x_{f}\right) / a_{1}$

\section{MODEL BASED PREDICTIVE CONTROL}

MBPC is a name of several different control techniques. All are associated with the same idea. The prediction is based on the model of the process, as it is shown in Fig. 2.

The target of the model-based predictive control is to predict the future behavior of the process over a certain horizon using the dynamic model and obtaining the control actions to minimize a certain criterion, generally [10]:

$$
J=\sum_{k=N_{1}}^{N_{2}}\left(M(t+k)-Y_{m}(t+k)\right)^{2}+\sum_{k=1}^{N_{u}}\left(\lambda_{k} \Delta U_{n}(t+k)\right)^{2}
$$

Signals $M(k+t), Y m(k+t), u(k+t)$ are the $t$-step ahead predictions of the process output, the reference trajectory and the control input, respectively. The values $N_{l}$ and $\mathrm{N}_{2}$ are the minimal and maximal prediction horizon of the controlled output, and $\mathrm{Nu}$ is the prediction horizon of the control input. The value of $N 2$ should cover the important part of the step response curve. The use of the control horizon $N u$ reduces the computational load of the method. The parameter $\square$ represents the weight of the control signal. At each sampling period only the first control signal of the calculated sequence is applied to the controlled process. At the next sampling time the procedure is repeated. This is known as the receding horizon concept.

The controller consists of the plant model, the optimization block, objective function and prediction block as shown in Fig. 2. The input and output constraints are:

$$
\begin{gathered}
u_{\min } \leq u_{i} \leq u_{\max }, \quad i=0, \ldots \ldots, N_{2}-1 \\
\Delta u_{\min } \leq \Delta u_{i} \leq \Delta u_{\max }, \quad i=0, \ldots . ., N_{2}-1 \\
y_{\min } \leq y_{i} \leq y_{\max }, \quad i=1, \ldots, N_{2}
\end{gathered}
$$

The ability to handle constraints is one of the key properties of MBPC and also causes its spread, use, and popularity in industry. MBPC algorithms are reported to be very versatile and robust in process control applications.

\section{NEURAL NETWORK PREDICTIVE CONTROL}

Neural networks have been applied very successfully in the identification and control of dynamic systems. The universal approximation capabilities of the multilayer perception make it a popular choice for modeling of nonlinear systems and for implementing of nonlinear controllers. The unknown function may correspond to a controlled system, and the neural network is the identified plant model. Two-layer networks, with sigmoid transfer functions in the hidden layer and linear transfer functions in the output layer, are universal approximations. The prediction error between the plant output and the neural network output is used as the neural network training signal. The neural network plant model uses previous inputs and previous plant outputs to predict future values of the plant output. The structure of the neural network plant model is given in the Fig. 3, where $u(t)$ is the system input, $y p(t)$ is the 
plant output, $y m(t)$ is the neural network model plant output, the blocks labeled TDL are tapped delay lines that store previous values of the input signal, $\mathbf{I W} i, j$ is the weight matrix from the input $j$ to the layer $i . \boldsymbol{L W} i, j$ is the weight matrix from the layer $j$ to the layer $i$.

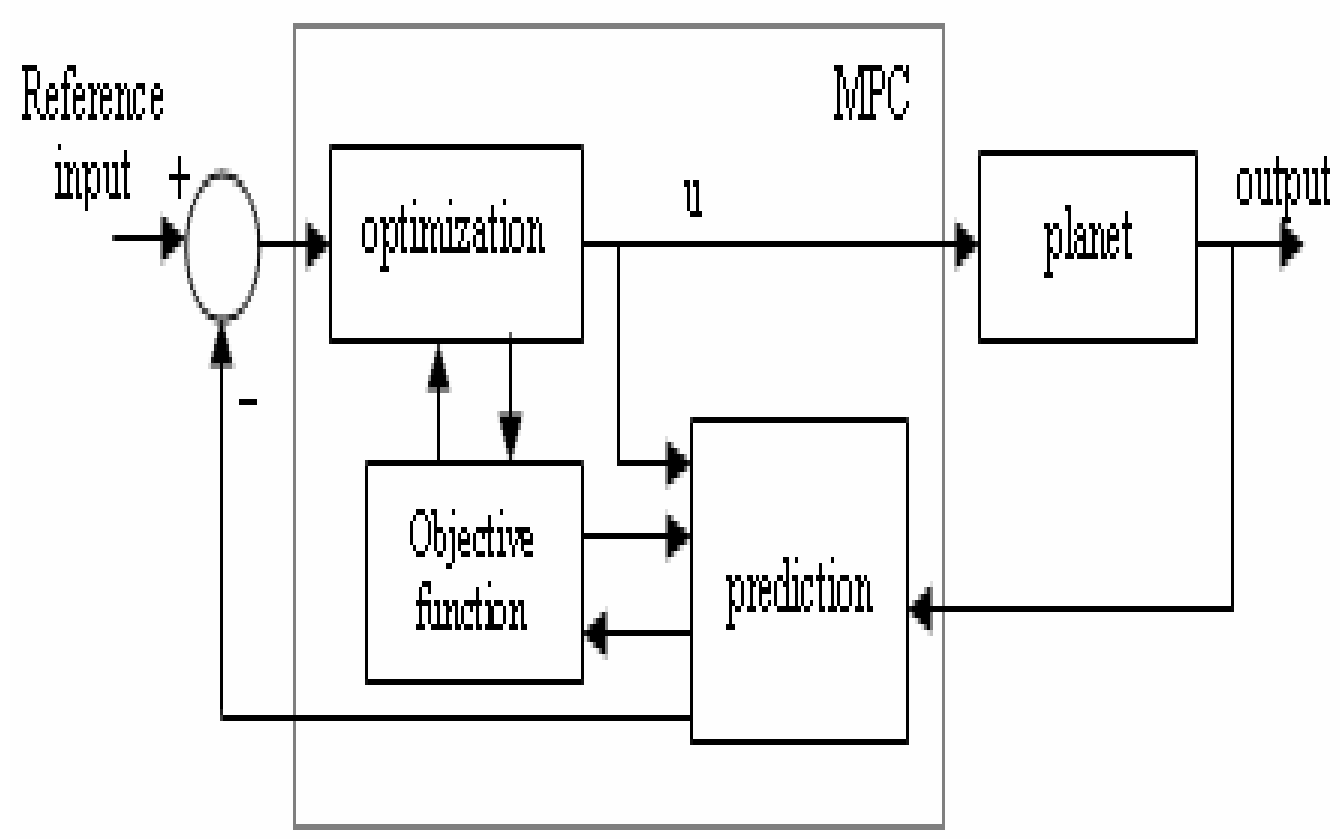

Fig. 2. Classical model-based predictive control scheme

This network can be trained off-line in batch mode, using data collected from the operation of the plant. The procedure for selecting the network parameters is called training the network. The Levenberg-Marquardt (LM) algorithm is very efficient for training. The LM algorithm is an iterative technique that locates the minimum of a function that is expressed as the sum of squares of nonlinear functions. It has become a standard technique for nonlinear least-squares problems and can be thought of as a combination of steepest descent and the Gauss-Newton method [17]. When the current solution is far from the correct one, the algorithm behaves like a steepest descent method: slow, but guaranteed to converge. When the current solution is close to the correct solution, it becomes a Gauss-Newton method.

Assumed functional relation which maps a parameter vector $P \in R^{m}$ to an estimated measurement vector $\hat{x}=f(p), \hat{x} \in R^{n}$. An initial parameter estimate po and a measured vector $\boldsymbol{x}$ are provided, and it is desired to find the vector $\hat{p}$ that best satisfies the functional relation $f$, i.e. minimizes the squared distance $e T e$ with $e=x \square \square \hat{x}$. The basis of the LM algorithm is a linear approximation to $f$ in the neighborhood of p. For a small $\left\|\delta_{p}\right\|$, a Taylor series expansion leads to the approximation $f\left(P+\delta_{p}\right) \approx f(P)+J \delta_{p}$ where $\boldsymbol{J}$ is the Jacobi matrix $\frac{\partial f(P)}{\partial P}$. Like all non-linear 
optimization methods, LM is iterative: initiated at the starting point po, the method produces a series of vectors $\mathbf{p} 1, \mathbf{p} 2, \ldots$, that converge towards a local minimize $\hat{p}$ for $f$. Hence, at each step, it is required to find the $\delta_{p}$ that minimizes the quantity $\left\|e-J \delta_{p}\right\|$. The sought $\delta_{p}$ is thus the solution of a linear least-square problem: the minimum is attained when $J \delta_{p} \square e \square$ is orthogonal to the column space of $J$. This leads to $J^{T}\left(J \delta_{p}-e\right)=0 \square \square$ which yields $\delta_{p}$ as the solution of the normal equations:

$$
J^{T} J \delta_{p}=J^{T} e
$$

The matrix $J^{T} J$ in the left hand side of Eqn. (19) is the approximate Hessian, i.e. an approximation to the matrix of second order derivatives. The LM method actually solves a slight variation of Eqn. (19), known as the augmented normal equations $N \delta_{p}=J^{T} e$, here the off-diagonal elements of $\mathrm{N}$ are identical to the corresponding elements of $J^{T} J$ and the diagonal elements are given by $N_{i i}=\mu+\left[J^{T} J\right]_{i i}$. The strategy of altering the diagonal elements of $J^{T} J$ is damping and $\square$ is referred to the damping term. If the updated parameter vector $p+\delta_{p}$ with $\delta_{p}$ computed from Eqn. (19) leads to a reduction of the error $e$, the update is accepted and the process repeats with a decreased damping term. Otherwise, the damping term is increased, the augmented normal equations are solved again and the process iterates until a value of $\delta_{p}$ that decreases error is found.

In LM, the damping term is adjusted at $f$ the following conditions are met. Each iteration to assure a reduction in the error $e$. The LM algorithm terminates when at least one $o$

1. The magnitude of the gradient of $e^{T} e$, i.e. $J^{T} e$ in the right hand side of Eqn. (19), drops below a threshold $\varepsilon l$.

2. The relative change in the magnitude of $\delta_{p}$ drops below a threshold $\varepsilon 2$.

3. The error $e^{T} e$ drops below a threshold $\varepsilon 3$.

4. A maximum number of iterations $k$-max is completed.

If a covariance matrix $\sum \square$ for the measured vector $x$ is available, the minimum is found by solving a weighted least squares problem defined by the weighted normal equations:

$$
J^{T} \sum J \delta_{p}=J^{T} \sum e
$$

Model predictive control using a neural network model for single-input, singleoutput systems has been studied by a few researchers and is outlined. For multivariable systems, the neural network MPC strategy was described using three fixed MLP models. The same strategy is used in our system using two MLP models with an adaptive model as shown in Fig.4. 


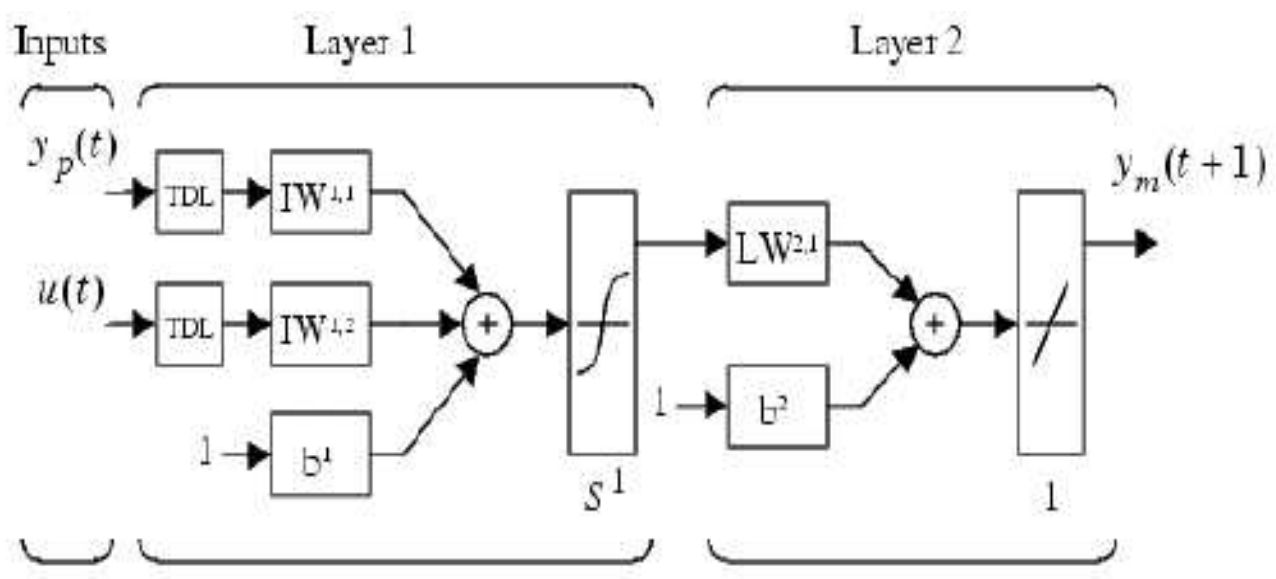

Fig. 3: Structure of the neural network plant model

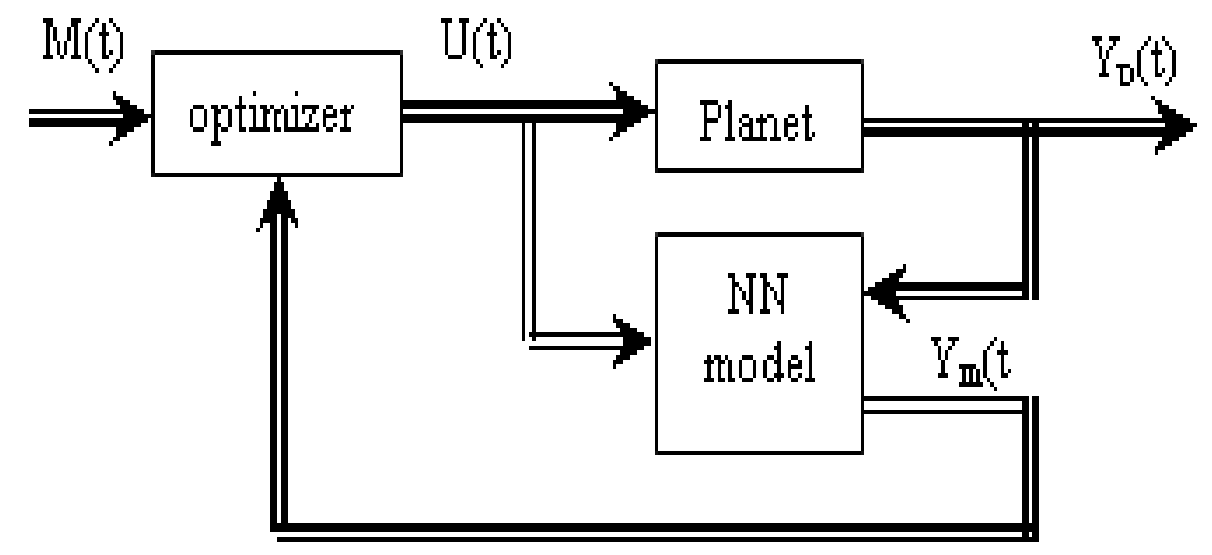

Fig.4: Multivariable NNMPC control strategy

\section{PID POWER SYSTEM STABILIZER}

PID controllers are dominant and popular and, have been widely used because one can obtain the desired system responses and they can control a wide class of systems. This may lead to the thought that the PID controllers give solutions to all requirements, but unfortunately, this is not always true [18]. In this work, the PID optimal tuning method used is found in Ref. [19]. In this method, the parameters of PID controller satisfying the constraints correspond to a given domain in a plane. The optimal controller lies on the curve. The design plot enables the identification of the PID controller for desired robust conditions, and in particular, gives the PID controller for lowest sensitivity. By applying this method, trade-off among high frequency sensor noise, low frequency sensitivity, gain and phase margin constraints are also directly available. 
The transfer function of a PID controller is given by:

$$
K(s)=K_{p}\left(1+\frac{1}{T_{I} s}+T_{D} s\right)
$$

where $K_{p}, \frac{K_{P}}{T_{I}}$ and $K_{P} T_{D}$ represent the proportional, integral and derivative gains of the controller respectively. Define $\omega_{n}=\frac{1}{\sqrt{T_{I} T_{D}}}$ and $\zeta=\frac{1}{2} \sqrt{\frac{T_{I}}{T_{D}}}$ as the controller's natural frequency and the damping coefficient, respectively. Then the PID transfer function can be written as:

$$
K(s)=K_{P} \frac{\omega_{n}^{2}+2 \zeta \omega_{n} s+s^{2}}{2 \zeta \omega_{n} s}
$$

The optimal PID controller parameters values were: $K_{p}=22, T_{I}=0.6$ and $K_{D}=12$

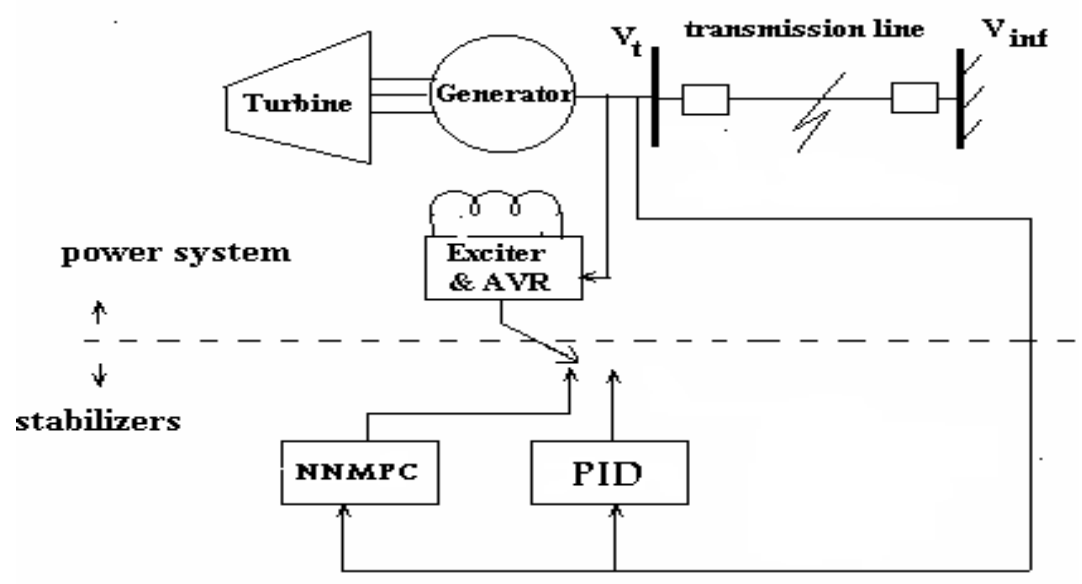

Fig. 5: Schematic diagram of power system model with different power system stabilizers

\section{SIMULATION RESULTS AND DISCUSSION}

The objective of this control is to stabilize the power system performance and minimize the deviation between the actual and reference field voltage. The cost function of Eqn. (18) will have the following form for the proposed system:

$$
J=\sum_{k=N_{1}}^{N_{2}}\left(V_{f}(t+k)-V_{\text {fpred }}(t+k)\right)^{2}+\sum_{k=1}^{N_{u}}\left(\lambda_{k} V_{\text {fref }}(t+k)\right)^{2}
$$

the constraints are chosen such that, the output voltage is normalized to be 1 , corresponds to output voltage. Thus,

$$
V_{r e f}-\varepsilon \leq u_{p} \leq V_{r e f}+\varepsilon \text {. }
$$


The controller using a neural network model to predict future power system responses and potential control signals is designed. Then, an optimization algorithm related to Eq. (23) computes the control signals that optimize future plant performance. The neural network plant model was trained using the Levenberg-Marquardt algorithm. The training data were obtained from the model of the power system model (1-7). The used model predictive control method was based on the receding horizon technique. The neural network model predicted the plant response over a specified time horizon. The predictions were used by a numerical optimization program to determine the control signal that minimizes performance criterion over the specified horizon. The controller was implemented using Matlab/Simulink sotware program.

Choosing power system parameters as given in Ref. [2] in a pu.as follows:

$$
\begin{aligned}
& X_{f}=1.1, \quad X_{d}-1.2, \quad X_{d}^{\prime}=0.291, \quad X_{k d}=1.1, \quad X_{m d}=1.0, \quad X_{q}=0.8 \\
& X_{k q}=0.8 \quad X_{m q}=0.6, \quad r_{m}=0.01, \quad r_{k d}=0.02, \quad r_{k q}=0.04, \quad r_{f}=0.0011 \\
& T_{d o}^{\prime}=2.65, \quad H=3.0, \quad T_{m o}=0.01, \quad r_{e}=0.0, \quad x_{e}=0.4, \quad w_{o}=377.0
\end{aligned}
$$

Applying the proposed NNMPC and PID controller to the power system under study as shown in Fig. 5. Fig. 6 shows the rotor speed deviation response due to 0.1pu. step disturbance at 0.5 lag power factor load with both PID and NN-MPC controller. Fig. 7 depicted the rotor speed deviation response due to $0.1 \mathrm{pu}$. step disturbance at -0.5 lead power factor load with both PID and NN-MPC controller. Fig.8 shows the rotor speed deviation response due to $0.1 \mathrm{pu}$. step disturbance at 0.8 lag power factor load with both PID and NN-MPC controller. Also, Fig. 9 shows the rotor speed deviation response due to $0.1 \mathrm{pu}$. step disturbance at -0.8 lead power factor load with both PID and NN-MPC controller. Moreover, the rotor speed deviation response due to 0.1pu. step disturbance at 0.8 lag power factor load with PID and NN-MPC controller with $20 \%$ increase in $X_{\mathrm{f}}$ and $\mathrm{X}_{\mathrm{d}}$. is shown in Fig. 10. Fig. 11 depicted the rotor speed deviation response due to $0.1 \mathrm{pu}$. step disturbance at -0.8 lead power factor load with PID and NN-MPC controller with $20 \%$ increase in $X_{\mathrm{f}}$ and $X_{\mathrm{d}}$. Fig. 12 shows the rotor speed deviation response due to $0.1 \mathrm{pu}$. step disturbance at -0.6 lead power factor load with PID and NN-MPC controller with $20 \%$ increase in $X_{\mathrm{f}}$ and $\mathrm{X}_{\mathrm{d}}$. Furthermore, the maximum overshoot $(\mathrm{MP})$, settling time $\left(\mathrm{T}_{\mathrm{s}}\right)$ and steady state error $\left(\mathrm{e}_{\mathrm{ss}}\right)$ are calculated in table 1 at different operating point.

\section{Table 1; The time settling and step- characteristic of different controller}

\begin{tabular}{|c|c|c|c|c|}
\hline \multirow{2}{*}{} & \multicolumn{2}{|c|}{$\begin{array}{c}\text { Vt=1 pu. }, \mathrm{Pf}=0.8 \\
\text { Lag power factor load }\end{array}$} & \multicolumn{2}{c|}{$\begin{array}{c}\mathrm{Vt}=1 \text { pu. }, \mathrm{Pf}=-0.5 \\
\text { Lead power factor load }\end{array}$} \\
\cline { 2 - 5 } & $\begin{array}{c}\text { With PID } \\
\text { control }\end{array}$ & With NN-MPC & $\begin{array}{c}\text { With PID } \\
\text { control }\end{array}$ & With NN-MPC \\
\hline$M P$ & $\mathbf{0 . 0 2 9}$ & $\mathbf{0 . 0 0 8}$ & $\mathbf{0 . 0 2 8}$ & $\mathbf{0 . 0 1 2}$ \\
\hline$T_{s}$ & $\mathbf{9 . 0}$ & $\mathbf{1 . 0}$ & $\mathbf{9 . 0}$ & $\mathbf{0 . 9}$ \\
\hline$e_{S S}$ & $\mathbf{0}$ & $\mathbf{0}$ & $\mathbf{0}$ & $\mathbf{0}$ \\
\hline
\end{tabular}


Where; $M P$ is the maximum peak; $T_{s}$ is the settling time, $e_{s s}$ is the steady state error

It is clear that from the above figures that the overshoot, undershoot with less time settling of the time response system in case of the proposed NNMPC controller are shorter and smaller than the case of PID controller. From table 1, the settling time with PID controller is $9 \mathrm{Sec}$. but with the proposed NNMPC is $1 \mathrm{Sec}$. Moreover, the steady state error is zero in both PID and NNMPC controllers.

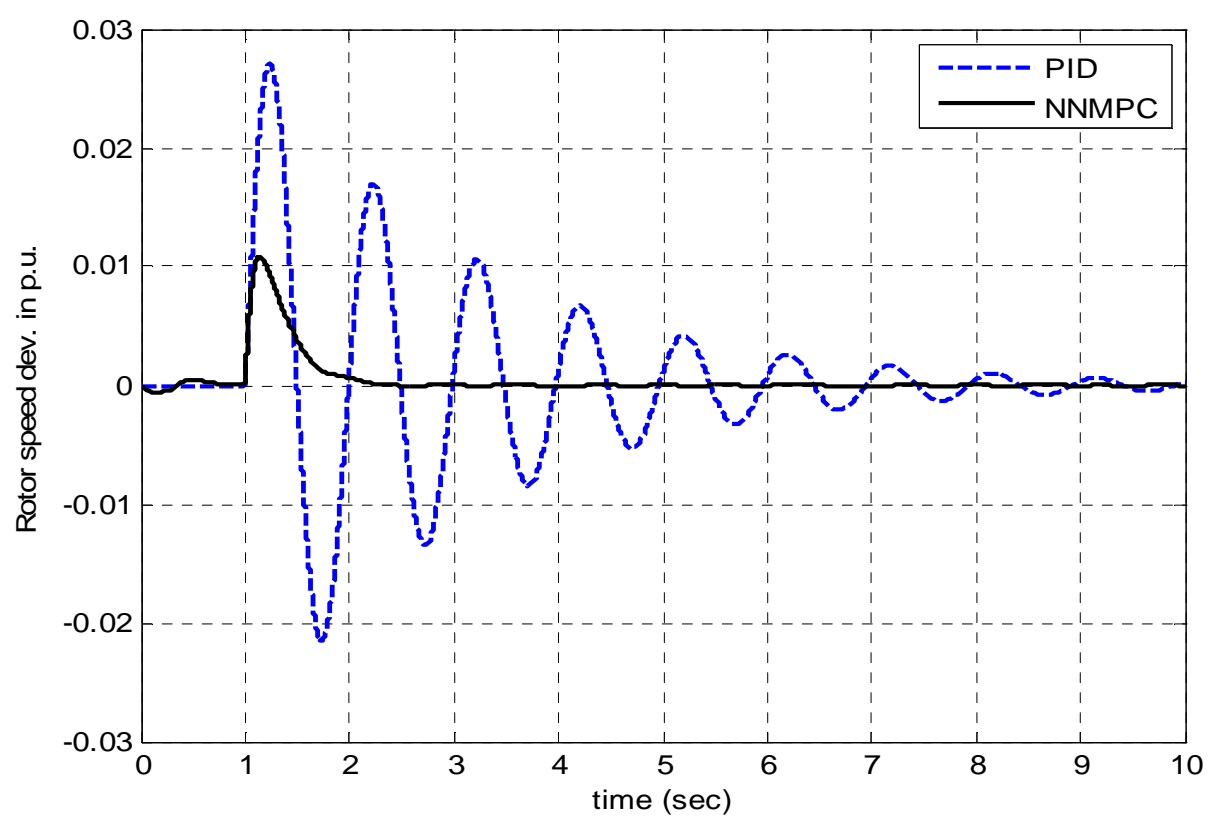

Fig. 6: Rotor speed deviation response due to $0.1 \mathrm{pu}$. step disturbance at 0.5 lag power factor load with PID and NN-MPC controller.

\section{CONCLUSIONS}

The scope of this paper is to investigate the potential improvements that can be achieved using neural network predictive control methodologies for the design of power system stabilizer. To validate the effectiveness of the proposed controller, a comparison among the PID controller and the proposed NN-MPC controller is obtained. Both the proposed NN-MPC and PID with the single synchronous machine connected to infinite bus power system is evaluated when both load and parameters changed. From the simulations results, it is seen that the proposed controller is robust and gives good transient as well as steady -state performances. The digital simulation results validate the effectiveness and powerful of the proposed NN-MPC controller compared with the PID stabilizer in terms of fast power system mechanical oscillation damping over a wide range of operating conditions and variations in system parameters. The time settling with the proposed NN-MPC stabilizer is smaller than the corresponding value with PID stabilizer. The maximum over and under shoot with the proposed NN-MPC stabilizer is less than the corresponding value with PID controller. 


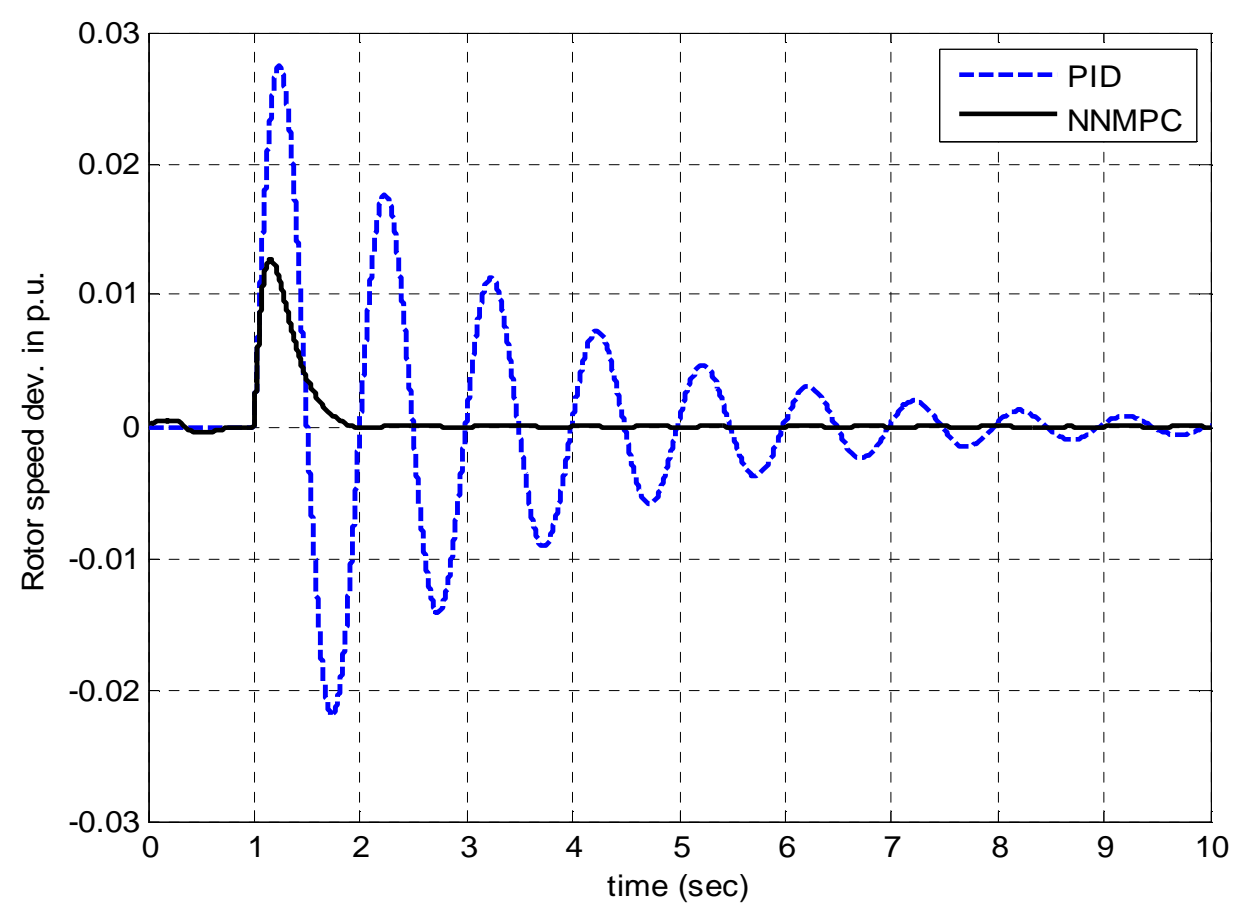

Fig. 7: Rotor speed deviation response due to $0.1 \mathrm{pu}$. step disturbance at -0.5 lead power factor load with PID and NN-MPC controller.

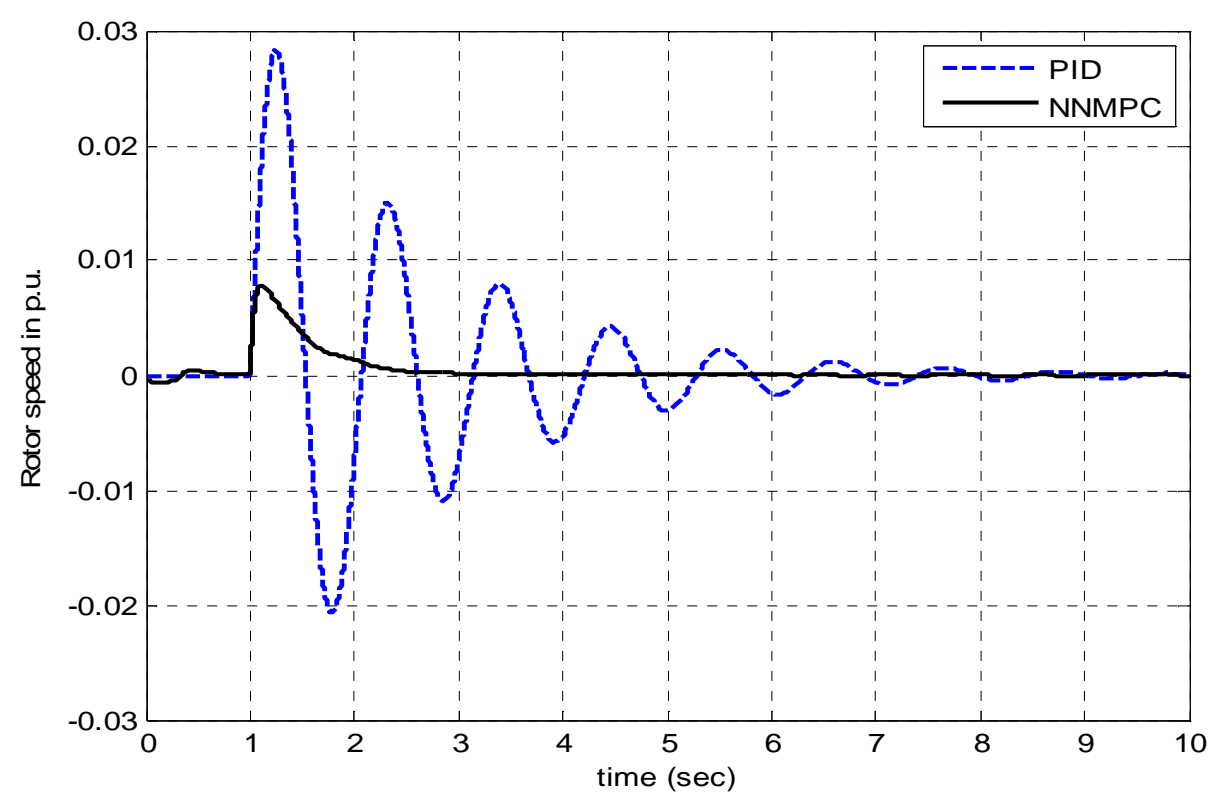

Fig. 8: Rotor speed deviation response due to $0.1 \mathrm{pu}$. step disturbance at 0.8 lag power factor load with PID and NN-MPC controller. 


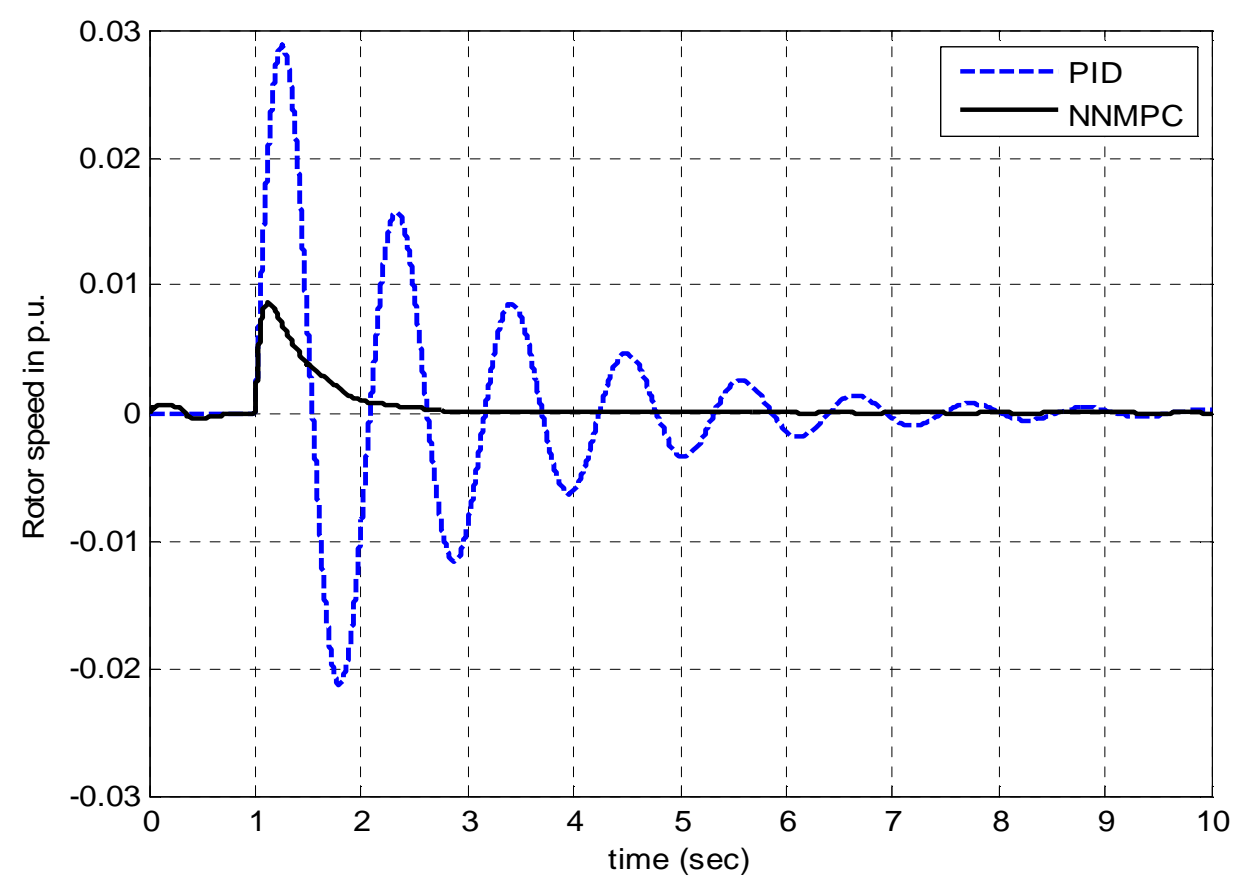

Fig. 9: Rotor speed deviation response due to $0.1 \mathrm{pu}$. step disturbance at -0.8 lead power factor load with PID and NN-MPC controller.

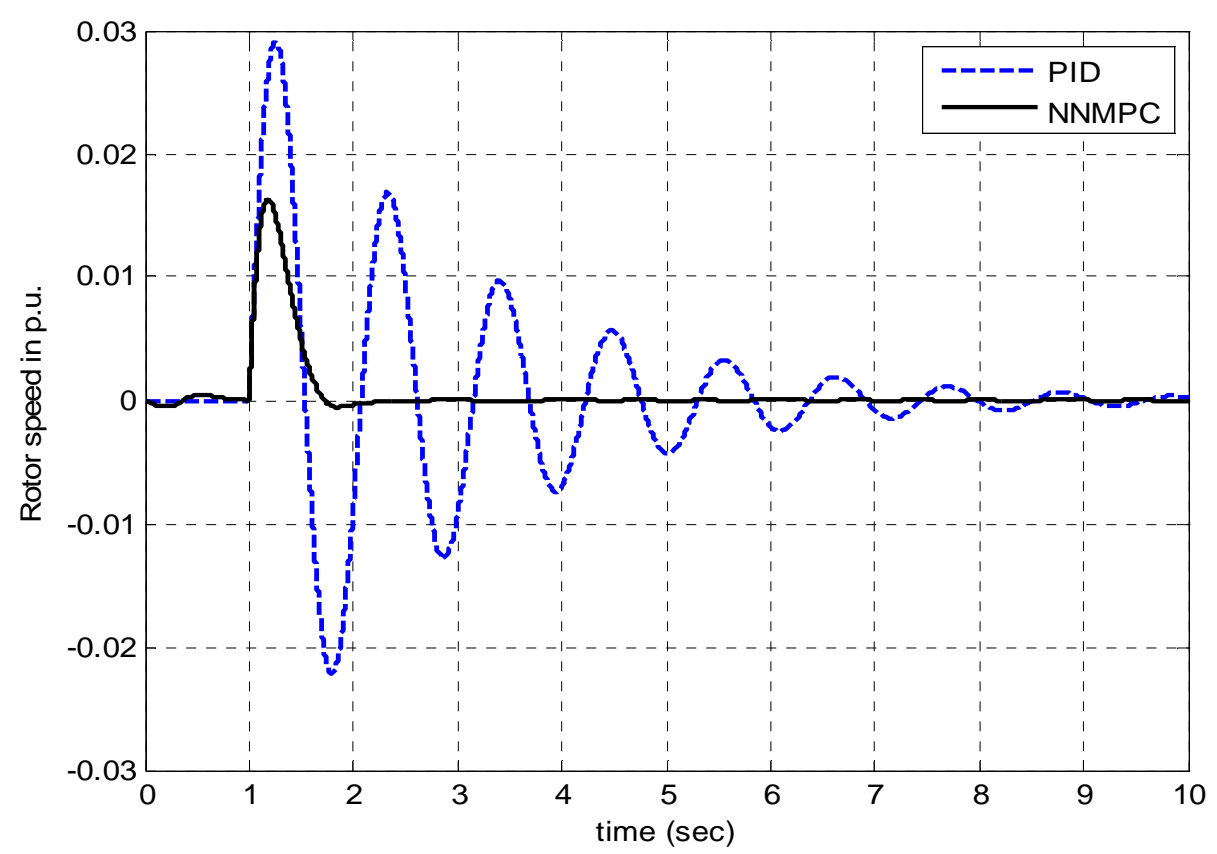

Fig. 10: Rotor speed deviation response due to 0.1 pu. step disturbance at 0.8 lag power factor load with PID and NN-MPC controller with $20 \%$ increase in $X_{\mathrm{f}}$ and $X_{\mathrm{d}}$. 


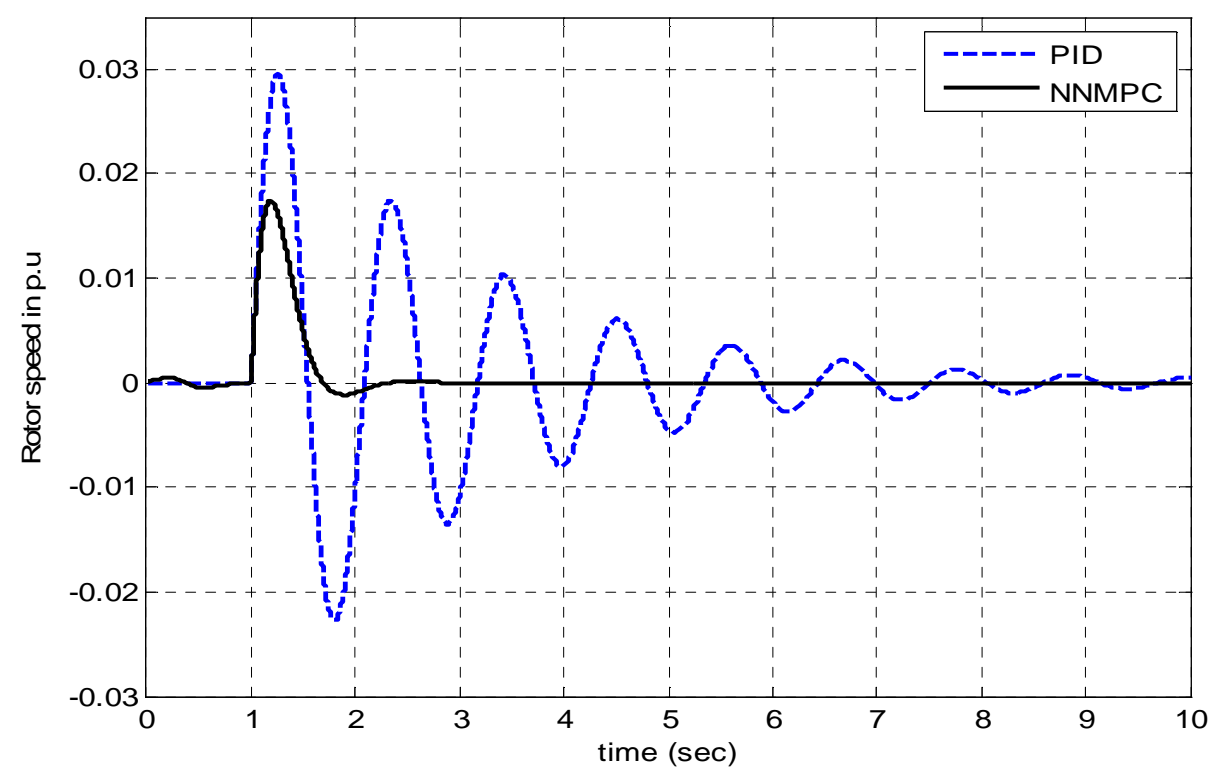

Fig. 11: Rotor speed deviation response due to $0.1 \mathrm{pu}$. step disturbance at -0.8 lead power factor load with PID and NN-MPC controller with with $20 \%$ increase in $\mathrm{X}_{\mathrm{f}}$ and $\mathrm{X}_{\mathrm{d}}$.

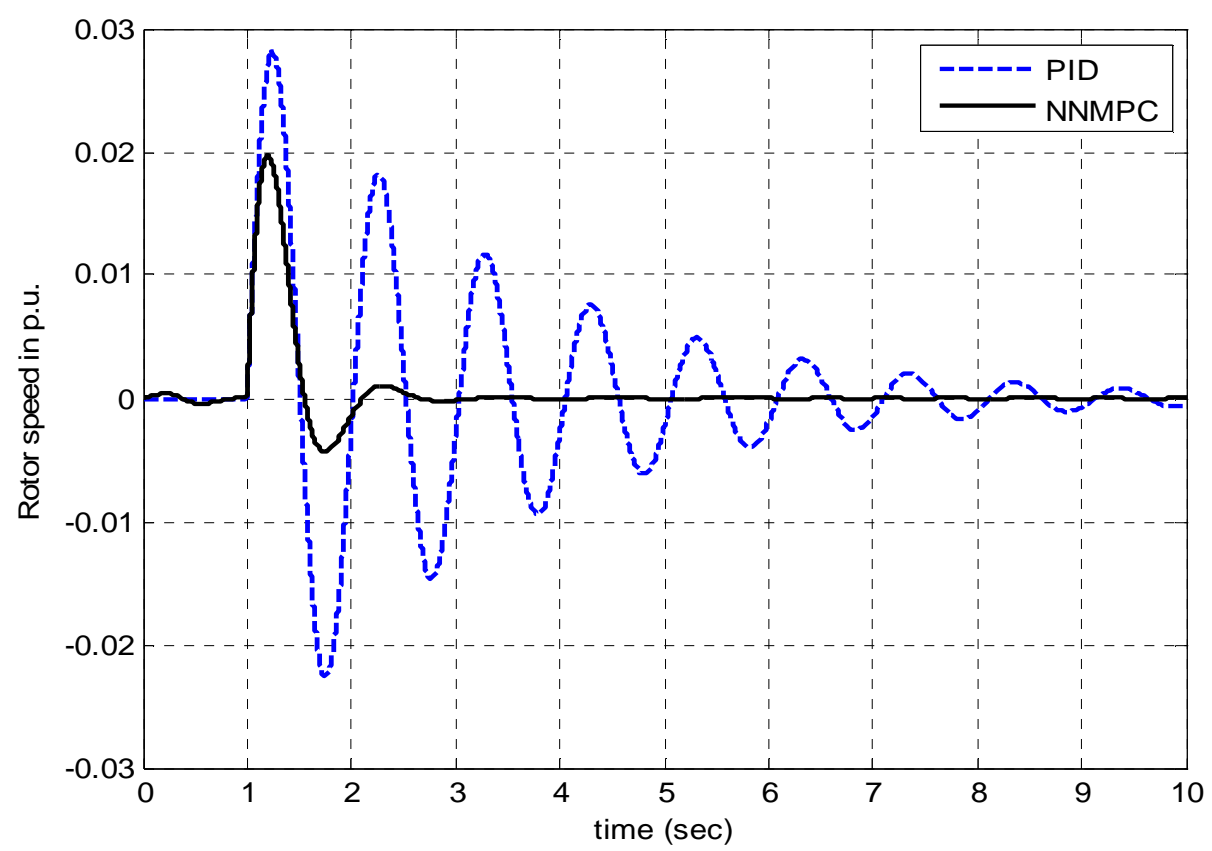

Fig. 12: Rotor speed deviation response due to $0.1 \mathrm{pu}$. step disturbance at -0.6 lead power factor load with PID and NN-MPC controller with with $20 \%$ increase in $\mathrm{X}_{\mathrm{f}}$ and $\mathrm{X}_{\mathrm{d}}$. 


\section{REFERENCES}

[1] A. S. Abd-Allah " Modelling of Saturated Synchronous Machines for steady-tate Stability Studies", Ph.D. Thesis ,Assiut University 1988.

[2] Ali M. Yousef "Design Of A Robust H2 Linear Quadratic Gaussian Controller For Power System Stabilization " Journal of Engineering sciences, Faculty of Engineering (JES), Assiut University, Vol. 33, No. 4, PP. 1547-1561, July 2005

[3] O. A. Solheim, "Design of optimal control system with prescribed eigenvalues", Int. J. Control, 15 (1972), PP 143-160.

[4] M.K. El-Sherbiny , M. M. Hassan, G.El-Saady and Ali M. Yousef " Optimal pole shifting for power system stabilization", Electric Power Systems Research Journal, No.66 PP. 253-258. 2003

[5] Wang, Y., D.J. Hill and G. Guo, "Robust decentralized control for multi-machine power system", IEEE Trans. on circuits and systems: Fund. Theory and Applications., Vol. 45, No. 3, 1998.

[6] Shayeghi, H, "Robust modified GA based multi-stage fuzzy LFC". Energy Conversion and Management., Vol. 48, pp 1656-1670, 2007.

[7] Shayegi, H., H.A. Shayanfar and O.P. Malik, " Robust decentralized neural networks based LFC in a deregulated power system". Elec. Power Syst. Res., Vol. 77, pp 241-251, 2007.

[8] Draeger, A., S. Engel and H. Ranke, 1995. "Model predictive control using neural networks", IEEE Control System Magazine, Vol. 15, pp 61-66, 1995.

[9] Gomm, J.B., J.T. Evans and D. Williams, "Development and performance of a neural network predictive controller". Control Engineering Practice, Vol. 5, No 1, pp 49-60, 1997.

[10] Shams Abad Frahani, M.A. Nekouei, and Mehdi Nikzad, "Predictive Control of a Single Link Flexible Joint Robot Based on Neural Network and Feedback Linearization". Australian Journal of Basic and Applied Sciences, Vol. 3, No 3, pp 2322-2333, 2009.

[11] Richalet JA, Rault A, Testud JD, Papon J "Model predictive heuristic control: applications to an industrial process". Automatica, Vol 14, pp 413-428, 1978.

[12] Cutler CR, Ramaker BL, "Dynamic matrix control - a computer control algorithm". Proc. Of Amer. Control Conf., WP5-B, 1980.

[13] Garcia CE, Morari M, "Internal model control-I. A unifying review and some new Results". Ind. Eng. Chem. Process Des. Dev. Vol 21, pp 308-323, 1982.

[14] Kuure-Kinsey M. , Cutright R. and Bequette B. W., "Computationally Efficient Neural Predictive Control based on a Feedforward Architecture". Industrial and Engineering Chemistry Research, Vol. 45 , pp. 8575-8582, 2006.

[15] Paisan Kittisupakorn, Piyanuch Thitiyasook, M.A. Hussain and Wachira Daosud, "Neural network based model predictive control for a steel pickling process". Journal of Process Control, Vol. 19, Issue 4, pp 579-590, 2009.

[16] Georgios Papafotiou, Tobias Geyer and Manfred Morari, "A hybrid model predictive control approach to the irect torque control problem of induction motors". international journal of robust and nonlinear control, Vol. 17, pp 15721589, 2007. 
[17] Alvaro R., De Pierro and Musheng Wei, "Some new properties of the equality constrained and weighted least squares problem". Linear Algebra and its Applications, Vol. 320, Issues 1-3, pp 145-165, 2000.

[18] Datta A., Ming-Tzu H. and Bhttacharyy S. P., "Structure and synthesis of PID controllers". Advanced in Industrial Control, Springer-Verlag London Limited, 2000.

[19] Kristiansson, B. and Lennartson, B., "Robust and optimal tuning of PID controllers", IEE Proc. Control theory and application, V 149, 2002, pp. 17-25.

\section{مثُبِّت نظامِ كهريائي معتمد على التحكم بشبكة الأعصاب التبوئيةٍ}

البحث الحالئ يقوم بفحص مثبتُ النظامِ الكهربائي مستندا على التحكم التتبوئي بشبكة الأعصاب

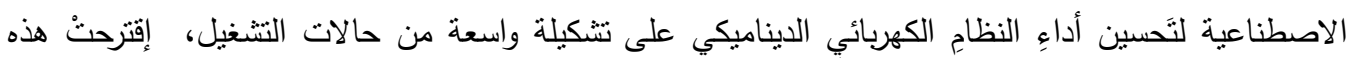

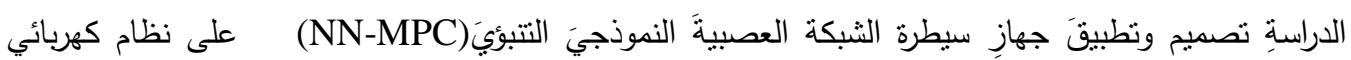

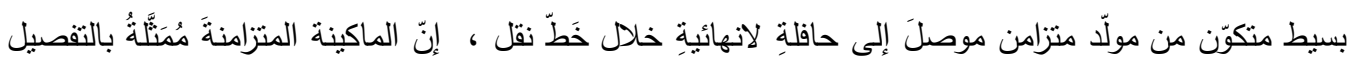

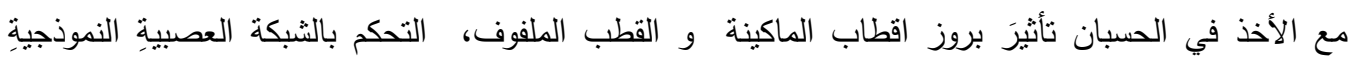

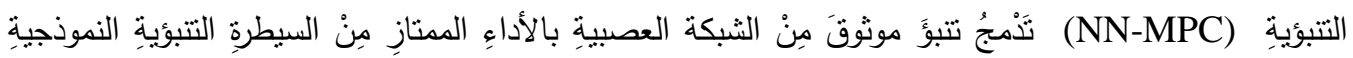
باستخدام طريقة ليفن مارك الاخطية النموذجية ، استعملت هذه السيطرة إنحرافَ سرعةِ الدورّان كإنثارة مرجعية ،

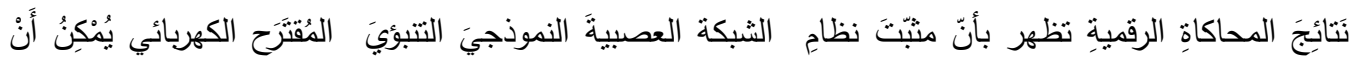

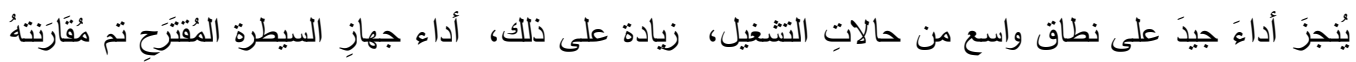

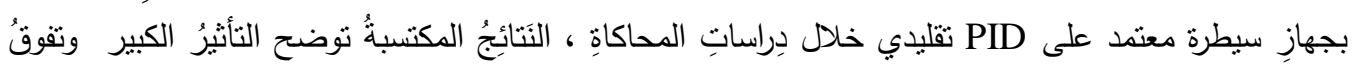

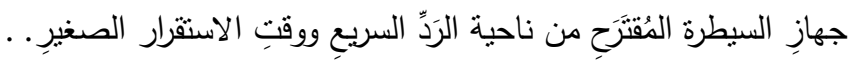

